\title{
Prostate cancer stromal cells and LNCaP cells coordinately activate the androgen receptor through synthesis of testosterone and dihydrotestosterone from dehydroepiandrosterone
}

\author{
Atsushi Mizokami, Eitetsu Koh, Kouji Izumi, Kazutaka Narimoto, \\ Masashi Takeda, Seijiro Honma ${ }^{1}$, Jinlu Dai ${ }^{2}$, Evan T Keller ${ }^{2}$ \\ and Mikio Namiki
}

Department of Integrative Cancer Therapy and Urology, Kanazawa University Graduate School of Medical Sciences,

13-1 Takaramachi, Kanazawa City 920-8640, Japan

${ }^{1}$ Teikoku Hormone MFG. Co., 1604 Shimosakunobe, Takatsu-ku, Kawasaki, Kanagawa 213, Japan

${ }^{2}$ Departments of Urology and Pathology, University of Michigan, Ann Arbor, Michigan, USA

(Correspondence should be addressed to A Mizokami; Email: mizokami@med.kanazawa-u.ac.jp)

\begin{abstract}
One of the mechanisms through which advanced prostate cancer (PCa) usually relapses after androgen deprivation therapy (ADT) is the adaptation to residual androgens in PCa tissue. It has been observed that androgen biosynthesis in PCa tissue plays an important role in this adaptation. In the present study, we investigated how stromal cells affect adrenal androgen dehydroepiandrosterone (DHEA) metabolism in androgen-sensitive PCa LNCaP cells. DHEA alone had little effect on prostate-specific antigen (PSA) promoter activity and the proliferation of LNCaP cells. However, the addition of prostate stromal cells or PCa-derived stromal cells (PCaSC) increased DHEA-induced PSA promoter activity via androgen receptor activation in the LNCaP cells. Moreover, $\mathrm{PCaSC}$ stimulated the proliferation of $\mathrm{LNCaP}$ cells under physiological concentrations of DHEA. Biosynthesis of testosterone or dihydrotestosterone from DHEA in stromal cells and $\mathrm{LNCaP}$ cells was involved in this stimulation of $\mathrm{LNCaP}$ cell proliferation. Androgen biosynthesis from DHEA depended upon the activity of various steroidogenic enzymes present in stromal cells. Finally, the dual $5 \alpha$-reductase inhibitor dutasteride appears to function not only as a $5 \alpha$-reductase inhibitor but also as a $3 \beta$-hydroxysteroid dehydrogenase inhibitor in LNCaP cells. Taken together, this coculture assay system provides new insights of coordinate androgen biosynthesis under the microenvironment of PCa cells before and after ADT, and offers a model system for the identification of important steroidogenic enzymes involved in PCa progression and for the development of the corresponding inhibitors of androgen biosynthesis.
\end{abstract}

Endocrine-Related Cancer (2009) 16 1139-1155

\section{Introduction}

Prostate cancer (PCa) is the most common malignancy and the second leading cause of cancer-related death of men in the United States (Jemal et al. 2008). Since advanced $\mathrm{PCa}$ is initially dependent upon androgens, androgen deprivation therapy (ADT) is the first choice for advanced PCa. Unfortunately, after an initial response to ADT, PCa eventually loses responsiveness to the androgen blockade and progresses into what is termed an androgen nonresponsive phenotype.

Multiple molecular mechanisms that could account for the development of resistance to ADT have been proposed (Feldman \& Feldman 2001), which typically invoke the androgen receptor (AR) as a key mediator in the progression of PCa (Takeda et al. 1996, Taplin \& Balk 2004). Moreover, alterations of AR itself, which are either absent or at low frequency in the original 
androgen-dependent state, result in an androgenhypersensitive situation where stimulation of $\mathrm{PCa}$ growth occurs at castrate levels of androgens (Taplin $\&$ Balk 2004). One of the AR alterations that occur is AR mutation that results in promiscuous ligand specificity (Veldscholte et al. 1990). Therefore, in addition to its normal ligands, testosterone and dihydrotestosterone (DHT), both androstenediol, a precursor of testosterone, and estradiol can activate the $\mathrm{AR}$ and stimulate the proliferation of $\mathrm{LNCaP}$ cells, which have a mutated AR (Mizokami et al. 2004, Arnold et al. 2005). Testosterone and the more active androgen DHT are important factors in PCa progression. These hormones are still present in $\mathrm{PCa}$ tissue after ADT. Specifically, when PCa patients are treated with ADT, serum testosterone and DHT decrease to less than one-tenth of pretreatment levels (Labrie et al. 1985). However, testosterone and DHT in PCa tissue are still present at $20-40 \%$ of pretreatment values (Labrie et al. 1985, Belanger et al. 1989, Forti et al. 1989, Mizokami et al. 2004, Nishiyama et al. 2004, Titus et al. 2005). These remaining androgens that are still present post-therapy may continue to promote AR activation and account for the observation that combination therapy with a LHRH agonist, to block androgen production, and an antiandrogen, to block ligand binding to the $\mathrm{AR}$, is more effective for $\mathrm{PCa}$ treatment than either therapy alone (Labrie et al. 1985, Akaza 2007, Labrie 2007).

Testosterone and DHT in PCa tissue after medical or surgical castration are synthesized locally in the prostate from dehydroepiandrosterone (DHEA) of adrenal origin (Labrie et al. 1985, Belanger et al. 1989, Forti et al. 1989, Mizokami et al. 2004, Nishiyama et al. 2004, Titus et al. 2005). The metabolism from DHEA to DHT in peripheral target tissues depends upon the level of expression of various steroidogenic enzymes in the specific cell types of converted to testosterone by $17 \beta$-hydroxysteroid dehydrogenase (17 $\beta$-HSD) and $3 \beta$-HSD. Testosterone is then converted to DHT by $5 \alpha$-steroid reductase (SRD5A) in the prostate (Andersson \& Russell 1990, Andersson et al. 1991, Labrie et al. 2005, Luu-The et al. 2008). Currently, 2 types of $3 \beta-H S D, 15$ types of $17 \beta$-HSDs, and 3 types of SRD5A have been identified and localized in various peripheral tissues, including the prostate, with specific expression patterns in each tissue (Luu-The et al. 2008, Uemura et al. 2008). For example, $3 \beta$-HSD and type $517 \beta$-HSD were localized in basal cells of alveoli, stromal cells, and endothelial cells of blood vessels of the prostate (Pelletier et al. 2001). Fung et al. (2006) have observed increased these tissues (Labrie et al. 2005). Adrenal DHEA is

expression of AKR1C3 (type 5 17 $\beta$-HSD) in $\mathrm{PCa}$ tissue, while Stanbrough et al. (2006) confirmed that ADT-resistant PCa and bone marrow metastases expressed increased levels of multiple genes responsible for androgen metabolism (HSD3B2, AKR1C3, SRD5A1, AKR1C2, AKR1C1, and UGT2B15). These studies provide support for the concept that PCa tissues can perform local biosynthesis of testosterone and DHT resulting in activation of the AR (Labrie 1991).

It remains unclear; however, in which cell types testosterone and DHT are converted from DHEA to other androgens in PCa tissue, although the products from DHEA and the relevant steroidogenic enzymes are definitively present in the prostate. In this study, we explored the hypothesis that PCa stromal cells contribute to the biosynthesis of testosterone and DHT in PCa. We demonstrated that testosterone and DHT synthesized from DHEA in stromal cells activated AR in PCa epithelial cells in a paracrine fashion and thus contribute to the development of ADT resistance in $\mathrm{PCa}$.

\section{Materials and methods}

\section{Isolation of stromal cells from prostate carcinoma tissue}

All studies were approved by the Institutional Review Board. We obtained informed consent for experimental use of all specimens obtained from prostate needle biopsy or surgical procedure. The characteristics of PCa patients are described in Table 1. Stromal cells were isolated using a modification of a previously described method (Krill et al. 1997). Briefly, small pieces of $\mathrm{PCa}$ tissue were minced with scissors and washed twice with PBS. The fragments were then digested in $0.25 \%$ trypsin-EDTA (Invitrogen) for $30 \mathrm{~min}$ at $37^{\circ} \mathrm{C}$. After digestion, the dispersed stromal cells were cultured in RPMI supplemented with $1 \%$ penicillin/streptomycin and 10\% FCS (Sigma; RPMI-10\% FCS) on $6 \mathrm{~cm}$ dishes. Bone-derived

Table 1 Characteristics of prostate cancer (PCa) patients on diagnosis

\begin{tabular}{llcl}
\hline $\begin{array}{l}\text { Stromal } \\
\text { cells }\end{array}$ & $\begin{array}{c}\text { PSA }(\mathrm{ng} / \mathrm{ml}) \\
\text { on diagnosis }\end{array}$ & $\begin{array}{c}\text { Gleason } \\
\text { score }\end{array}$ & $\begin{array}{c}\text { Stage on } \\
\text { diagnosis }\end{array}$ \\
\hline PCaSC-1 & 4799 & $5+5$ & T3a, N0, M1 \\
PCaSC-2 & 263 & $4+4$ & T3b, N0, M0 \\
PCaSC-5 & 76.9 & $4+3$ & T3a, N0, M1 \\
PCaSC-6 & 46.4 & $4+4$ & T3a, N1, M0 \\
PCaSC-7 & 648 & $4+3$ & T4, N1, M1 \\
PCaSC-8 & 246 & $4+5$ & T4, N0, M1 \\
PCaSC-9 & 180 & $5+4$ & T3b, N0, M0 \\
\hline
\end{tabular}


stromal cells 1 (BDSC-1) were obtained from the 11th rib of a 48-year-old man during left adrenalectomy for pheochromocytoma. BDSC-2 were obtained from the 11 th rib of a 58-year-old man during left nephroureterectomy for localized ureteral cancer. These bone samples were cut into bone chips and further processed with a bone grinder (Lu et al. 2004). Bone chips were then cultured in RPMI-10\% FCS like prostate-derived stromal cells.

\section{Cell culture and cell proliferation assay}

LNCaP cells were cultured in DMEM including phenol red-5\% FCS (DMEM-5\% FCS). Normal prostatederived stromal cells, PrSC, commercially available (Cambrex, East Rutherford, NJ, USA) were cultured using SCGM BulletKit (Cambrex). Twenty-four hours after $3 \times 10^{4}$ LNCaP cells were seeded on 12-well plates, aliquots of $3 \times 10^{4}$ stromal cells were plated onto Cell Culture Inserts $(1.0 \mu \mathrm{m}$ pore size 12-well format; Becton Dickinson, Franklin Lakes, NJ, USA) with DMEM, including phenol red-5\% charcoal-stripped FCS (CCS; Hyclone, Logan, UT, USA) in 12-well plates for $24 \mathrm{~h}$. Cells were then treated with DHEA (Sigma) and cultured for 4 days. As a positive control, $\mathrm{LNCaP}$ cells were treated with $0.1 \mathrm{nM}$ DHT for 4 days for $24 \mathrm{~h}$ without stromal cells. Medium and reagents were replaced every 2 days. At the end of the culture period, cells were trypsinized and counted in triplicate using a hemocytometer. All coculture studies were performed in DMEM-5\% CCS. These experiments were performed at least twice to obtain reproducible data.

\section{Coculture, transfection, and luciferase assay}

To evaluate AR transcriptional activity, $24 \mathrm{~h}$ after plating $5 \times 10^{4}$ cells on 12 -well plates in DMEM including phenol red-5\% CCS, LNCaP cells were transfected using Lipofectamine transfection reaction (Invitrogen) using $0.4 \mu \mathrm{g}$ luciferase reporter plasmid, pGL-5.8PSAp, driven by a $5.8 \mathrm{~kb}$ PSA promoter including androgen-response elements (Mizokami et al. 2000). Twelve hours after transfection, LNCaP cells were cocultured with $5 \times 10^{4}$ stromal cells for $12 \mathrm{~h}$, followed by the addition of indicated concentration of DHEA for $24 \mathrm{~h}$. Cells were then harvested $24 \mathrm{~h}$ after the addition of reagents and lysed in luciferase lysis buffer (Promega). As a positive control, transfected LNCaP cells were treated with $0.1 \mathrm{nM}$ DHT for $24 \mathrm{~h}$ without stromal cells. To block AR and SRD5A activity, we used $1 \mu \mathrm{M}$ bicalutamide and $5 \mu \mathrm{M}$ dutasteride (Dut; Nacalai Tesque, Kyoto, Japan). To knockdown AR expression in LNCaP cells by RNA interference, $5 \times 10^{4} \mathrm{LNCaP}$ cells were transfected with $20 \mathrm{nM}$ non-target (NT) siRNA, AR siRNA-1, or AR siRNA-2 (Invitrogen) using RNAiMAX (Invitrogen) for $12 \mathrm{~h}$, and $\mathrm{LNCaP}$ cells were transfected with pGL3PSAp-5.8 for $12 \mathrm{~h}$. Then after changing the medium, transfected LNCaP cells were cocultured with or without PrSC. Consequently, cells were treated with or without $100 \mathrm{nM}$ DHEA (+) for $24 \mathrm{~h}$. As a positive control, cells were treated with $0.1 \mathrm{nM}$ DHT for $24 \mathrm{~h}$. For knockdown of AR expression in PrSC by RNA interference, we transfected $3 \times 10^{5}$ PrSC on a $6 \mathrm{~cm}$ dish with $50 \mathrm{nM}$ RNAi or AR RNAi (5'-CAUAGUGACACCCAGAAGCUUCAUC-3'; Invitrogen) for $48 \mathrm{~h}$ with Lipofectamine RNAiMAX. Transfected cells were counted, and $5 \times 10^{4}$ siRNA-transfected PrSC were cocultured with $5 \times 10^{4}$ LNCaP cells transfected with pGL3PSAp-5.8 $12 \mathrm{~h}$ before coculture. Total RNA was extracted from the aliquot of PrSC transfected with AR siRNA. Knockdown of AR expression was confirmed by reverse transcription (RT)-PCR analysis. These experiments were performed at least twice to provide reproducible data.

\section{Quantitative analysis of androgens in the medium by LC-ESI-MS/MS}

Before harvesting cells, we collected the cultured medium and frozen it at $-30{ }^{\circ} \mathrm{C}$ until LC-ESI-MS/MS was performed as previously described (Mizokami et al. 2004). For LC-ESI-MS/MS, $0.5 \mathrm{ml}$ of the cultured medium was diluted with $0.5 \mathrm{ml}$ distilled water, and then $5 \mathrm{ng}$ androstenediol- ${ }^{2} \mathrm{H}_{4}\left(\mathrm{~A}-\mathrm{d}_{4}\right), 5 \mathrm{ng}$ $\left[16,16,17-{ }^{2} \mathrm{H}_{3}\right]$-testosterone $(100 \mathrm{pg}),\left[17,16,16-{ }^{2} \mathrm{H}_{3}\right]-$ DHT $(100 \mathrm{pg}),\left[2,2,4 \alpha, 6-{ }^{2} \mathrm{H}_{4}\right]$-DHEA $(200 \mathrm{pg})$, $\left[2,2,4,6,6,16,16-{ }^{2} \mathrm{H}_{7}\right]$-androstenedione $(100 \mathrm{pg})$, and $\left[2,2,4,6-{ }^{2} \mathrm{H}_{4}\right]$-adiol (100 pg) as internal standards were added to the individual samples. LC-ESI-MS/MS was performed using an API-4000 triple stage quadrupole mass spectrometer equipped with an ESI ion source (Applied Biosystems, Foster City, CA, USA) and an Agilent 1100 HPLC system (Agilent Technologies, Santa Clara, CA, USA) with HTC PAL auto-sampler (CTC Analytical, Zwingen, Switzerland). The assay was validated to ensure that the result was within the $20 \%$ range of accuracy and precision. We confirmed that endogenous DHEA, adiol, adione, testosterone, and DHT in DMEM-5\% CCS were below detectable methods.

\section{RNA extraction and RT-PCR}

Twenty-four hours after plating, $5 \times 10^{4} \mathrm{LNCaP}$ cells or stromal cells were treated with or without $10^{-8} \mathrm{M}$ DHT for $24 \mathrm{~h}$ at which time total RNA was purified with RNeasy mini kit (Qiagen). cDNA was made by 
RT of $200 \mathrm{ng}$ each total RNA using ThermoScript RT-PCR system (Invitrogen). Each cDNA sample was amplified with ExTaq (Takara, Otsu, Japan). The sense and antisense primers used and RT-PCR conditions are shown in Table 2. The amplified PCR products were visualized using electrophoresis on a $1.5 \%$ agarose gel. For quantification of mRNA expression, real-time PCR was performed according to the manufacturer's instructions and using the LightCycler TaqMan Master Solution, PCR primers, and Universal probe (Roche Applied Science). The gene expression in each sample was quantified as the yield of the target gene relative to that of the glyceraldehyde-3-phosphate dehydrogenase (GAPDH) gene.

\section{Statistical analysis}

Student's $t$-test, for bivariate comparisons, or ANOVA with Fisher's least significant difference post hoc test, for multivariate comparisons, were used to determine the statistical significance of differences of proliferation and luciferase assays. ${ }^{*} P<0.05$ was considered statistically significant.

\section{Results}

\section{Effect of DHT and DHEA on LNCaP cells in the presence of stromal cells}

In order to investigate AR activity, we transfected LNCaP cells with a luciferase expression plasmid driven by the prostate-specific antigen (PSA) promoter, pGL3PSAp-5.8, and performed luciferase assay because this method is simple, effective, and highly sensitive compared with ELISA for PSA protein and quantification of mRNA by RT-PCR (Mizokami et al. 2004). When LNCaP cells transfected with pGL3PSAp5.8 were treated with DHEA, PSA promoter activity was induced in a dose-dependent manner as previously described (Fig. 1A; Mizokami et al. 2004). However, high concentrations of DHEA were needed to induce PSA promoter activity. On the other hand, coculture of LNCaP cells with normal prostate-derived PrSC increased DHEA-induced PSA promoter activity in direct relation to the number of added PrSC (Fig. 1A). At the addition of $40000 \mathrm{PrSC}, 100 \mathrm{nMDHEA}$-induced PSA promoter activity increased threefold.

To study the effect of DHEA and of PrSC on LNCaP proliferation, LNCaP cells were cocultured with PrSC in chambers separated by a membrane and treated with DHEA for 4 days (Fig. 1B). LNCaP cell proliferation in the absence of PrSC peaked at $0.1 \mathrm{nM}$ DHT as previously described (Mizokami et al. 2004). LNCaP cell proliferation in the absence of PrSC was stimulated by DHEA in a dose-dependent manner as previously described (Mizokami et al. 2004). LNCaP cell proliferation was stimulated by coculture with PrSC in the absence of DHEA, which suggested that some factors secreted from PrSC stimulated the proliferation of LNCaP cells. The addition of 10-30 nM DHEA to the coculture of LNCaP cells and PrSC induced greater proliferation of LNCaP cells compared with the addition of PrSC alone. The induction of proliferation produced by DHEA was the same that could be attained by $0.1 \mathrm{nM}$ DHT, which stimulates maximal proliferation as previously described (Mizokami et al. 2004). At $100 \mathrm{nM}$ DHEA, the LNCaP cell proliferation began to decrease. This finding reflects the previously reported observation that DHT induces a biphasic response on LNCaP cell growth (Mizokami et al. 2004).

To determine whether the effect of DHEA on PSA promoter activity in the presence of PrSC is mediated through the AR present in LNCaP cells, PrSC, or both, we first used the antiandrogen bicalutamide to block AR. Bicalutamide $(1 \mu \mathrm{M})$ blocked DHEA-induced PSA promoter activity in the LNCaP and PrSC coculture, indicating that the DHEA-induced PSA promoter activity required the AR (Fig. 1C). However, this experiment does not indicate whether the impact on LNCaP AR or PrSC AR or both is what mediates the effect. Accordingly, we next blocked AR expression in LNCaP cells to determine whether the LNCaP AR was required for DHEA-mediated induction of the PSA promoter. We cotransfected $\mathrm{LNCaP}$ cells with AR siRNA expression plasmids and pGL-5.8PSAp and treated cells with DHEA in the absence and presence of PrSC. Transfection of LNCaP cells with AR siRNA resulted in $>90 \%$ decrease in AR expression (Fig. 1D). Knockdown of AR expression in LNCaP cells diminished DHEA-induced PSA promoter activation in both the absence and presence of PrSC (Fig. 1D). This observation suggests that LNCaP AR expression is required for DHEA-mediated PSA activation both in LNCaP cells alone and the increase of DHEA-mediated activation of the PSA promoter in the presence of PrSC (as observed in Fig. 1A). To determine whether DHEA also mediates its effects on $\mathrm{LNCaP}$ cells through a requirement for $\mathrm{AR}$ in the PrSC, we knocked down AR expression in PrSC using AR siRNA, which resulted in decreasing AR expression $>90 \%$ (Fig. 1E). Coculture of PrSC transfected with AR shRNA and LNCaP had no impact on DHEA-induced PSA promoter compared with coculture of PrSC transfected with NT control shRNA. These results indicate that DHEA action was increased in the presence of PrSC by a mechanism other than via AR in PrSC cells, such as paracrine factors produced in PrSC from DHEA metabolites (Fig. 1E right). 


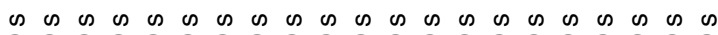

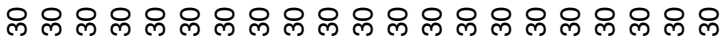

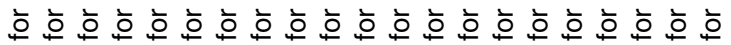

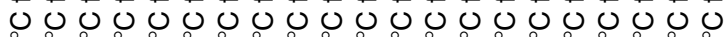
א.

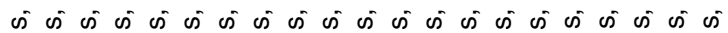

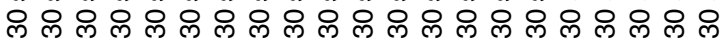

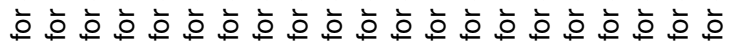

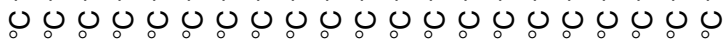

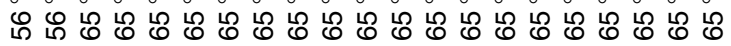

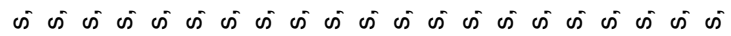

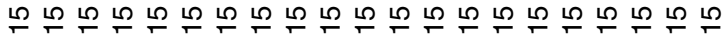

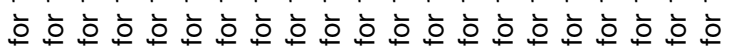

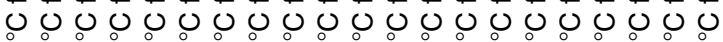

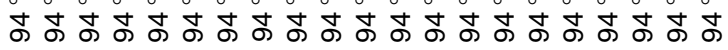

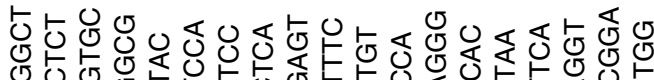

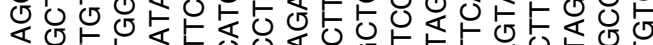

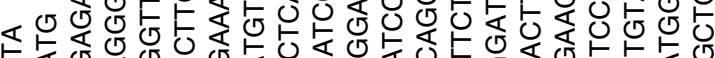

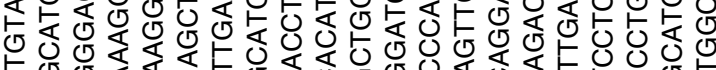

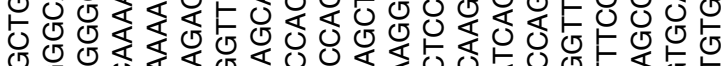

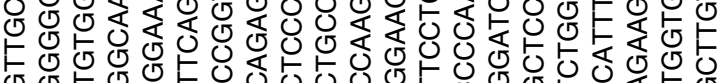

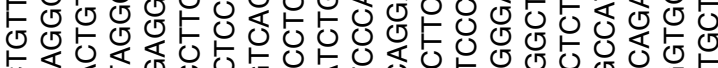

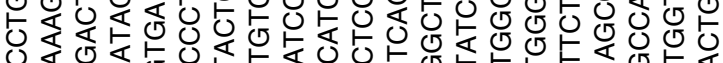

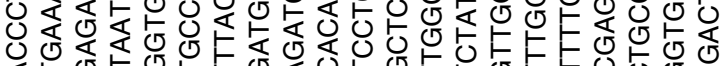

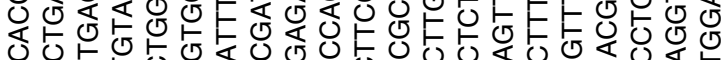

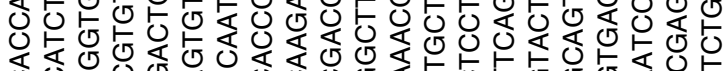

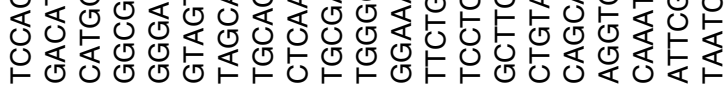

\begin{abstract}
作
\end{abstract}

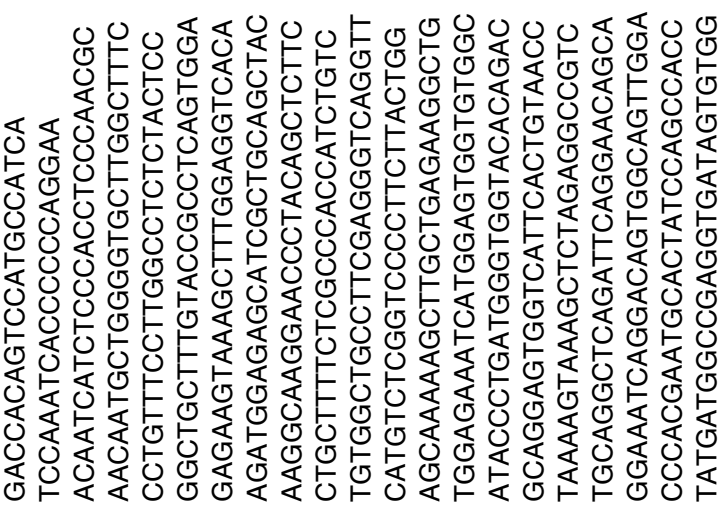

O1

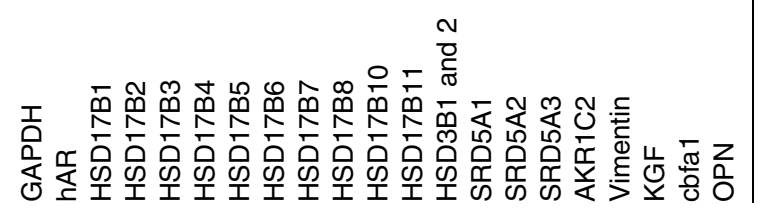



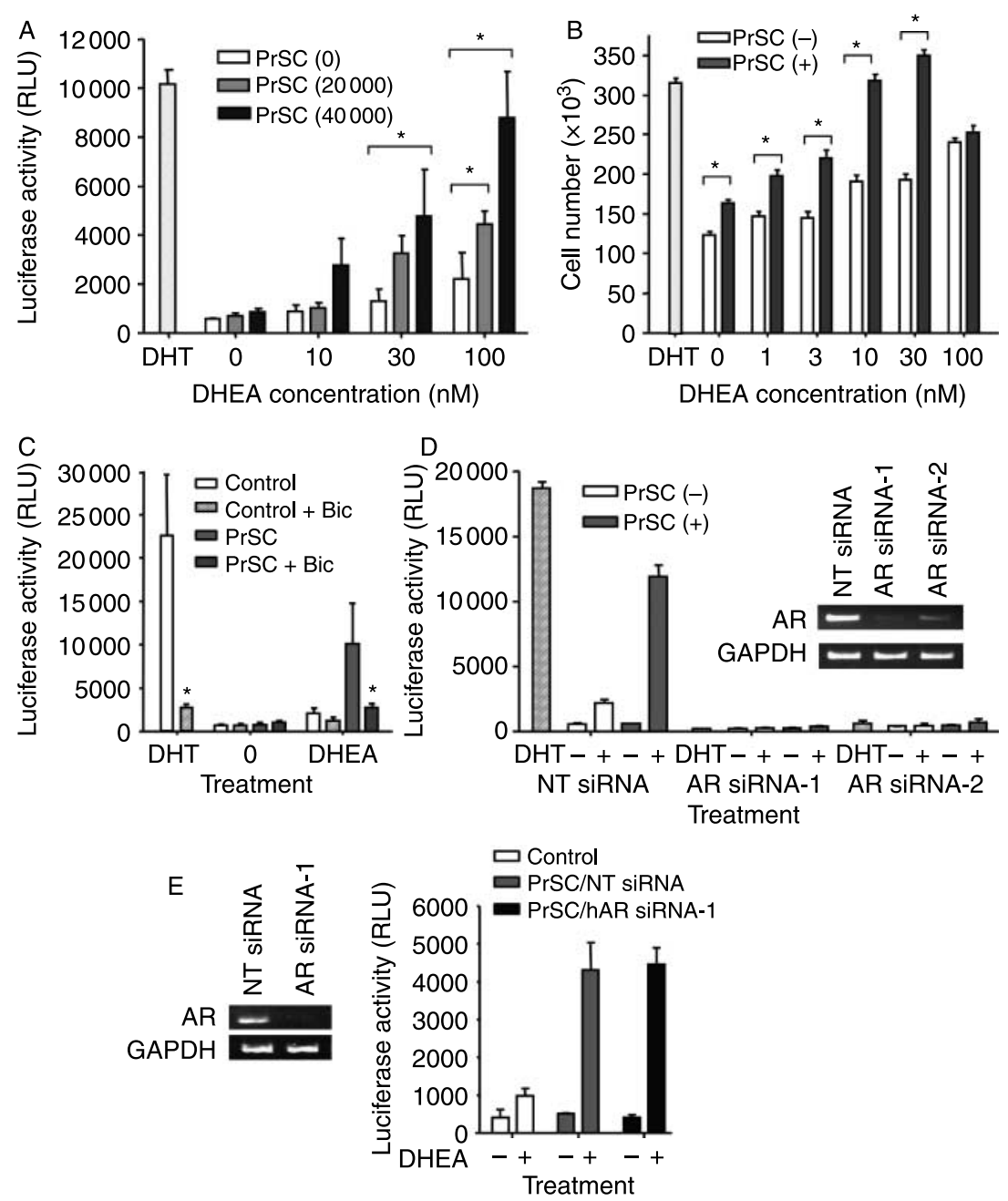

Figure 1 Effect of PrSC on PSA promoter activity and proliferation of LNCaP cells in the presence of DHEA. (A) After $5 \times 10^{4} \mathrm{LNCaP}$ cells were transfected with $0.4 \mu \mathrm{g}$ pGL-5.8PSAp for $12 \mathrm{~h}$, the cells were cocultured in DMEM- $5 \%$ CCS with $0,2 \times 10^{4}$, or $4 \times 10^{4}$ PrSC cells for $12 \mathrm{~h}$. Consequently, both cells were treated with DHEA for $24 \mathrm{~h}$ and cells were lysed. As a positive control, transfected LNCaP cells were treated with $0.1 \mathrm{nM}$ DHT for $24 \mathrm{~h}$ without PrSC (column of oblique lines). The absolute luciferase activities were measured. (B) LNCaP cell proliferation in the absence or presence of PrSC. Twenty-four hours after $3 \times 10^{4} \mathrm{LNCaP}$ cells were cultured on the lower chamber, PrSC cells were seeded on the upper chamber. Twelve hours later, cells were treated with increasing concentrations of DHEA for 4 days and counted. As a positive control, LNCaP cells were treated with $0.1 \mathrm{nM} \mathrm{DHT}$ for 4 days for $24 \mathrm{~h}$ without PrSC (column of oblique lines). (C) LNCaP cells transfected with pGL3PSAp-5.8 were cocultured with or without PrSC for $12 \mathrm{~h}$. Those cells were treated with $100 \mathrm{nM}$ DHEA in the absence or presence of $1 \mu \mathrm{M}$ bicalutamide for $24 \mathrm{~h}$, and then luciferase activities were measured. Transfected LNCaP cells were also treated with $0.1 \mathrm{nM}$ DHT with or without bicalutamide for $24 \mathrm{~h}$ as a positive control. (D) AR knockdown of AR in LNCaP cells. After AR, LNCaP cells were knocked down using AR siRNA-1 or AR siRNA-2, cells were transfected with pGL3PSAp-5.8 for $12 \mathrm{~h}$. Transfected LNCaP cells were cocultured with or without PrSC.

Consequently, cells were treated with or without $100 \mathrm{nM} \mathrm{DHEA}(+)$ for $24 \mathrm{~h}$. As a positive control, cells were treated with $0.1 \mathrm{nM}$ DHT for $24 \mathrm{~h}$. (E) LNCaP cells transfected with pGL3PSAp-5.8 were cocultured with PrSC and transfected with 50 nM NT siRNA or AR siRNA-1 for $48 \mathrm{~h}$. The aliquot of transfected PrSC was used for RT-PCR analysis of AR knockdown. Those cells were treated with $100 \mathrm{nM}$ DHEA for $24 \mathrm{~h}$, and then luciferase activity was measured. These coculture experiments were performed at least twice with reproducible data. The data are presented as the mean \pm S.D. of triplicate measurements.

\section{Effect of PCa-derived stromal cells on LNCaP cells}

To further investigate whether the ability of PrSC to promote androgen activity in the LNCaP cells was prostate specific, we examined stromal cells from different tissues. Coculture of LNCaP cells with human bone marrow-derived stromal cells and lung-derived stromal cells enhanced DHEA-induced PSA promoter activity, although these effects were somewhat lower than with PrSC (Fig. 2A).

We next investigated whether PCa-derived stromal cells (PCaSC) could regulate DHEA-stimulatory 


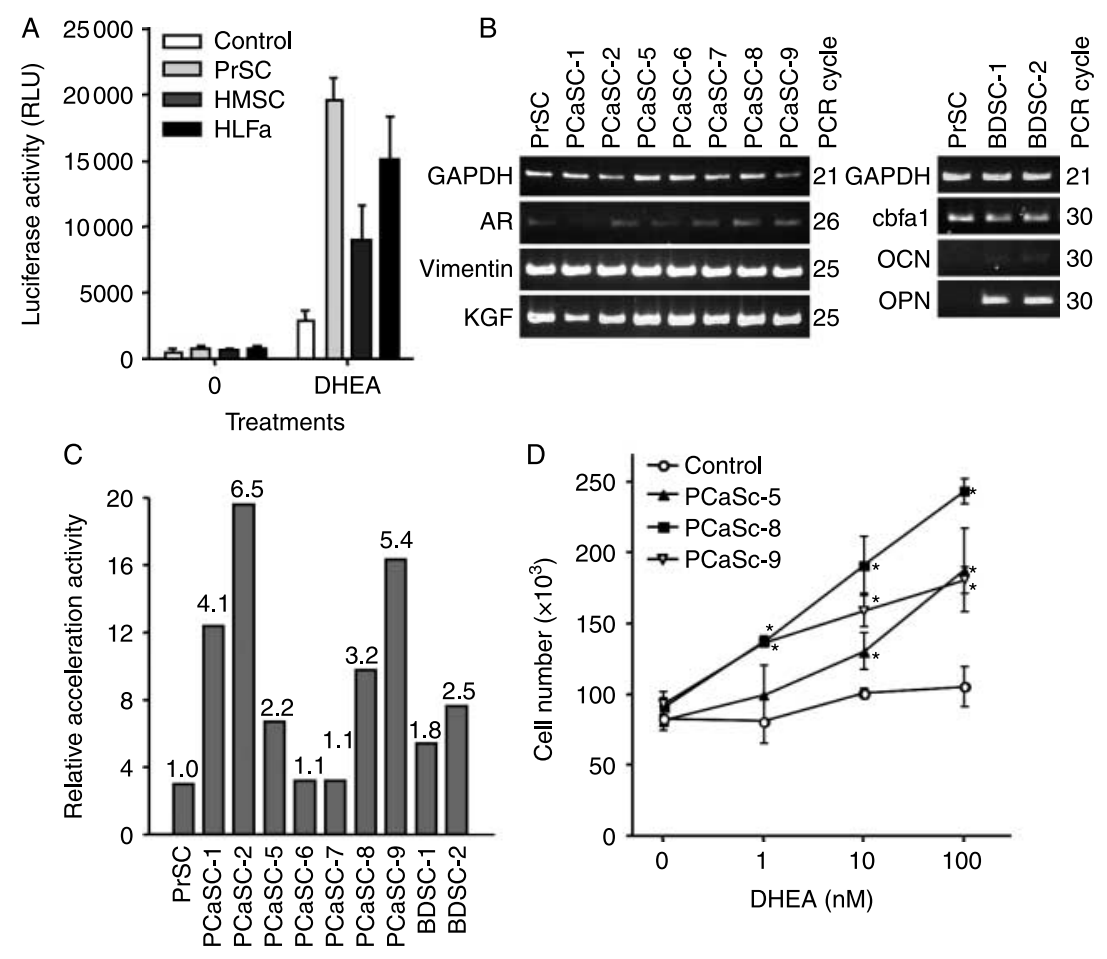

Figure 2 Effect of stromal cells from different tissues and PCa tissues on DHEA and DHT-induced PSA promoter activity and proliferation. (A) Effect of stromal cells from different tissues on DHEA and DHT-induced PSA promoter activity. Stromal cells from different tissues, PrSC, HMSC, and HLFa, were cocultured with LNCaP cells transfected with pGL3PSAp-5.8 and treated with $100 \mathrm{nM}$ DHEA for $24 \mathrm{~h}$, and luciferase activities were measured. (B) Confirmation of stromal cells from different PCa patients and the normal rib bone. Expression of vimentin and KGF was observed in prostate-derived stromal cells by RT-PCR. Expression of cbfa1 and osteopontin (OPN) was also observed in BDSC-1 and BDSC-2 by RT-PCR. (C) Effect of stromal cells from different PCa patients and the normal rib bone on PSA promoter activity. Columns indicate the relative acceleration ratio compared with $100 \mathrm{nM}$ DHEA alone in the absence of stromal cells, and the number above each column represents relative induction ratio compared with PrSC. (D) Effect of different PCaSCs on LNCaP cell proliferation. Twenty-four hours after $3 \times 10^{4} \mathrm{LNCaP}$ cells were cultured on the lower chamber, PCaSC-5, -8 , or -9 cells were seeded on the upper chamber. Twelve hours later, cells were treated with increasing concentrations of DHEA for 4 days and counted. Medium was changed every 2 days, and DHEA was added to medium. These coculture experiments were performed at least twice with reproducible data. The data are presented as the mean \pm S.D. of triplicate measurements.

effects on PSA promoter in LNCaP cells. We performed primary cultures of several PCaSCs from PCa tissue obtained by prostate needle biopsy for diagnosis (pathology and stage of patients are described in Table 1). All PCaSCs expressed vimentin and keratinocyte growth factor, thus confirming their stromal origin (Fig. 2B). All PCaSCs increased DHEAinduced PSA promoter activity. PCaSC-1, $-2,-5,-8$, and -9 stimulated greater DHEA-induced PSA promoter activity than the PrSC (Fig. 3C). Since PCa often metastasizes to bones, we also cocultured LNCaP cells with BDSC-1 and -2 . To confirm bone origin of the BDSC, we examine for expression of osteoblast factors. RT-PCR confirmed that core-binding factor $\alpha 1$, osteopontin, and osteocalcin were expressed in both BDSC-1 and -2, indicating that they were of bone origin (Fig. 2B). Both BDSCs increased PSA promoter activity induced by DHEA at a level 5.4-7.6-fold higher than observed with PrSC (Fig. 2C).

We next investigated in further detail how coculture with PCaSCs affected the proliferation of $\mathrm{LNCaP}$ cells in the presence of DHEA. When LNCaP cells were cultured without stromal cells, more than 10 nM DHEA was necessary to stimulate cell proliferation (Fig. 1B). Furthermore, when LNCaP cells were cocultured with PCaSC-5, -8 , or -9 in the absence of DHEA, the proliferation of $\mathrm{LNCaP}$ cells was barely stimulated (compare Fig. 1B with Fig. 2D). In contrast, the addition of DHEA to the coculture of PCaSC-5, -8 , or -9 with LNCaP cells stimulated LNCaP cell proliferation similar to the induction of the PSA promoter activity as described in Fig. 2C (Fig. 2D). This effect was seen even at low DHEA concentration $(1 \mathrm{nM})$ in the $\mathrm{LNCaP}$ cells cocultured with PCaSC-8 and -9 . 

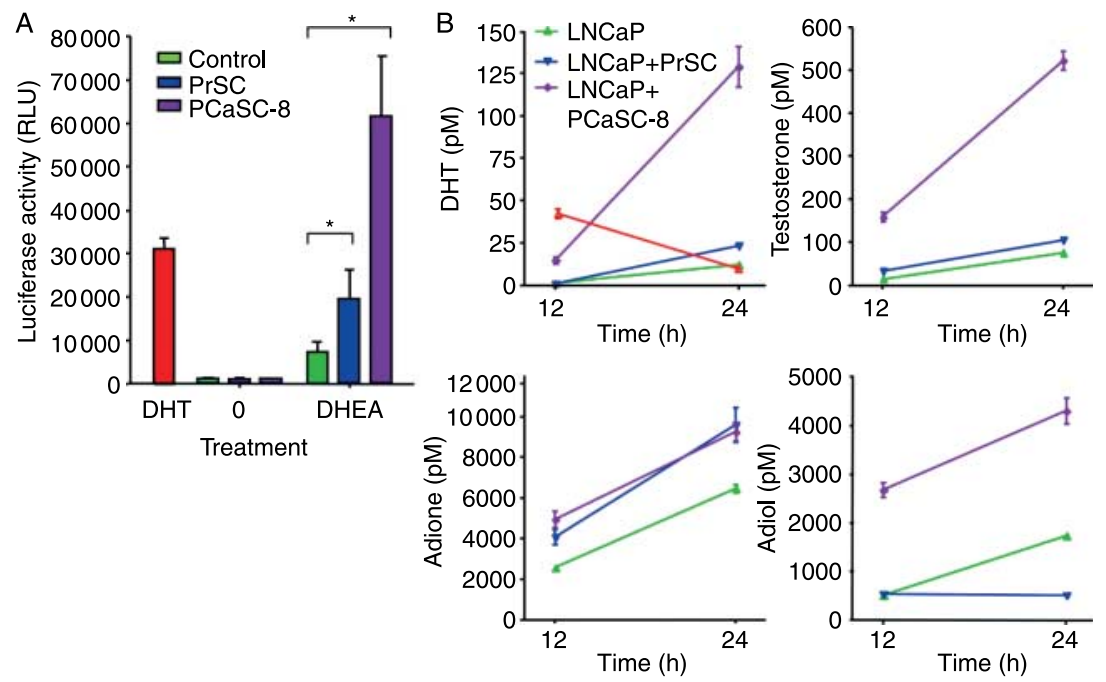

Figure 3 Androgen biosynthesis from DHEA in PrSC and PCaSC-8. (A) LNCaP cells transfected with pGL3PSAp-5.8 were cocultured with PrSC or PCaSC-8, treated with $100 \mathrm{nM}$ DHEA for $24 \mathrm{~h}$, and measured luciferase activity as described in Fig. 1. As a positive control, transfected LNCaP cells were treated with $0.1 \mathrm{nM} \mathrm{DHT}$ for $24 \mathrm{~h}$ (red column). These coculture experiments were performed at least twice with reproducible data. (B) Concentration of testosterone, DHT, adione, and adiol in the medium used for coculture with LNCaP and stromal cells after treating with $100 \mathrm{nM}$ DHEA. Twelve hours after starting culture of $5 \times 10^{4} \mathrm{LNCaP}$ cells with or without $5 \times 10^{4} \mathrm{PrSC}$ or PCaSC- 8 cells, $100 \mathrm{nM}$ DHEA was added to the medium. Then aliquots of medium were collected after 12 and $24 \mathrm{~h}$ for measuring concentration of testosterone, DHT, adione, and adiol by LC-ESI-MS/MS. A red line shows concentration of DHT in the medium used for monoculture of LNCaP cells after treating with $0.1 \mathrm{nM}$ DHT as described in Fig. 3A. The lower limit of quantitation of testosterone, DHT, DHEA, adione, and adiol was 5, 2.5, 5, 2.5, and 1 pg/assay respectively. The data are presented as the mean \pm s.D. of triplicate measurements.

\section{Androgen concentration in medium after coculture with stromal cells}

We hypothesized that the change of AR activity in the LNCaP cells induced by stromal cells in the presence of DHT and DHEA was influenced by the change in metabolism of androgens caused by stromal cells. To test this hypothesis, we examined the change in the concentrations of various androgens in the culture medium following coculture with stromal cells. After transfection with pGL-5.8PSAp, LNCaP cells cocultured with PrSC or PCaSC-8 were treated with $100 \mathrm{nM}$ DHEA. When LNCaP cells were cocultured with PrSC or PCaSC- 8 in the presence of DHEA, PSA promoter activity was activated more than 2.5 and 8.0 times when LNCaP cells were cultured alone respectively (Fig. 3A).

In the absence of DHEA, we could not detect testosterone and DHT in $\mathrm{LNCaP}$ and stromal cells using LC-MS/MS (data not shown). When LNCaP cells were cultured alone, the addition of $100 \mathrm{nM}$ DHEA resulted in media concentrations of $75.3 \mathrm{pM}$ testosterone and $12.4 \mathrm{pM}$ DHT in $24 \mathrm{~h}$ (Fig. 3B upper graphs). The addition of PrSC increased the concentration of testosterone and DHT in the medium to 104.6 and $23.6 \mathrm{pM} 24 \mathrm{~h}$ after the addition of $100 \mathrm{nM}$ DHEA respectively (Fig. 3B upper graphs). Moreover, coculture of LNCaP cells with PCaSC- 8 increased testosterone and DHT to 522.6 and $128.9 \mathrm{pM} 24 \mathrm{~h}$ after the addition of DHEA respectively (Fig. 3B upper graphs). The degree of increase in testosterone and DHT by coculture corresponded with DHEA-induced PSA promoter activity in the presence or absence of stromal cells as observed in the previous experiments.

To examine how DHEA was metabolized to testosterone in this culture system, we measured the concentration of intermediate metabolites, androstenedione (adione), and androstenediol (adiol) in the medium (Fig. 3C lower graphs). LNCaP monoculture contained $6456 \mathrm{pM}$ adione at $24 \mathrm{~h}$ from the addition of $100 \mathrm{nM}$ DHEA, whereas in the presence of stromal cells it was $\sim 9500 \mathrm{pM}$. This finding indicates that there was more $3 \beta$-HSDs activity in the coculture as opposed to the LNCaP monoculture (Fig. 3C lower graphs). We also found that the concentration of adiol in medium from the $\mathrm{LNCaP}$ and PrSC coculture was reduced compared with $\mathrm{LNCaP}$ monoculture. In contrast, the concentration of adiol synthesized in the PCaSC- 8 and LNCaP coculture in the presence of DHEA was increased to $4374 \mathrm{pM}$ at $24 \mathrm{~h}$. These data indicate that DHEA is converted into testosterone mainly via adione in the presence of PrSC and via both adione and adiol in the presence of PCaSC-8. 


\section{Expression of androgen biosynthesis enzymes}

Several enzymes are involved in the conversion pathway of DHEA to testosterone and DHT. Accordingly, we quantified mRNA expression level of $\mathrm{AR}$ and androgen biosynthesis enzymes in $\mathrm{LNCaP}$, PrSC, and BDSC (Fig. 4). Real-time PCR analysis revealed that $\mathrm{AR}$ expression level of all stromal cells was less than ten times that of the levels in $\mathrm{LNCaP}$ cells. Types 1 and $23 \beta$-HSD, which catalyzes the transformation of DHEA into adione and adiol to testosterone, were expressed in $\mathrm{LNCaP}$ cells and barely detectable in all stromal cells. Stromal cells expressed types 2 and 4 17 $\beta$-HSD at relatively high level. The level of expression of types 2 and $417 \beta-H S D$, which catalyzes the transformation of testosterone into adione, was different among stromal cells. Type 3 $17 \beta$-HSD, which is mainly expressed in the testes and catalyzes the transformation of adione into testosterone (Geissler et al. 1994), was expressed in LNCaP cells and all stromal cells at a very low level. The expression
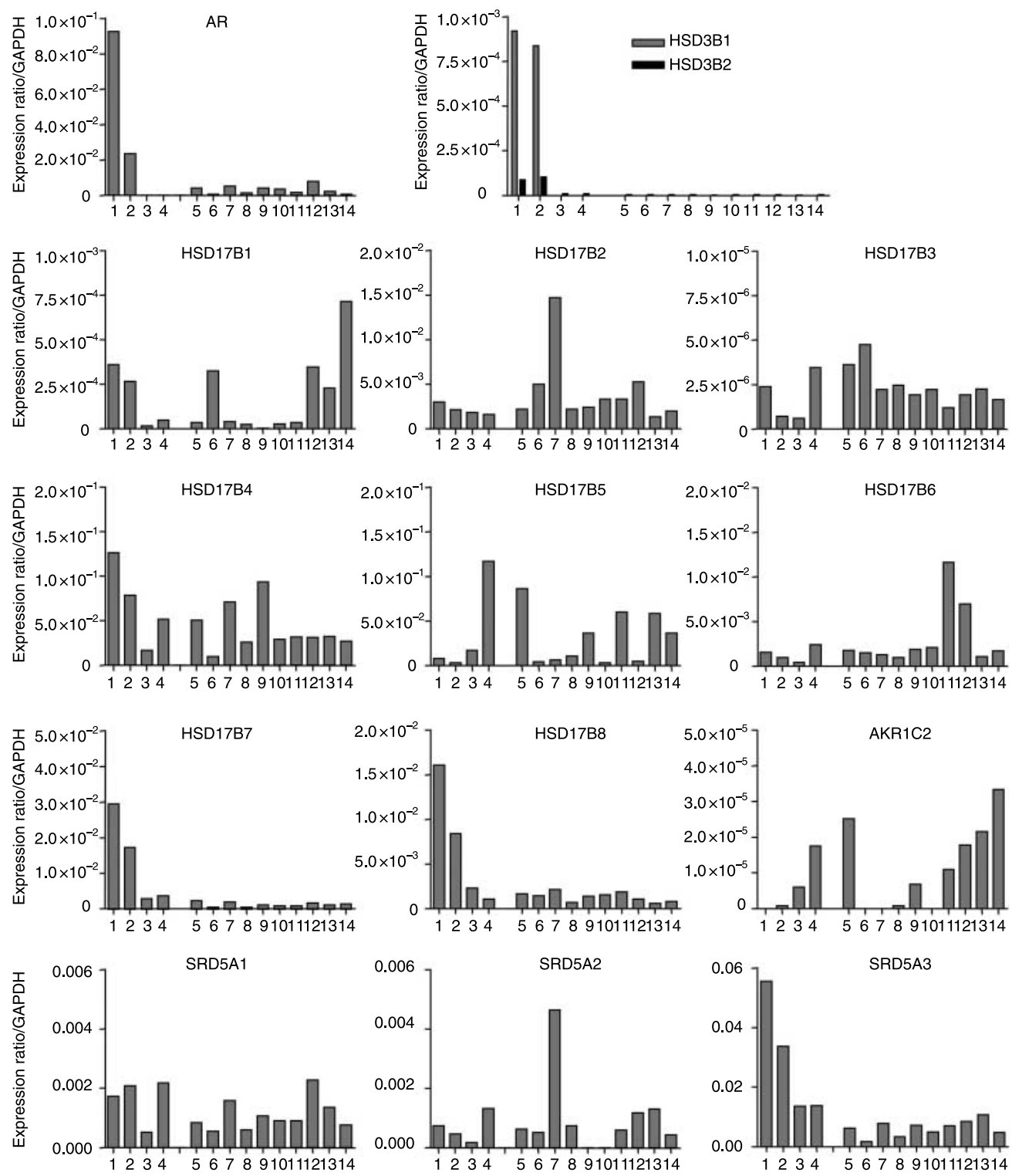

Figure 4 Real-time RT-PCR analysis of AR and androgen biosynthesis enzymes mRNA in LNCaP cells and stromal cells. Expression of AR, various HSD17s, HSD3B1 and 2, SRD5As, and AKR1C2 mRNA in various stromal cells was confirmed using realtime RT-PCR analysis. 1, LNCaP cells treated without androgen for $24 \mathrm{~h}$ in DMEM-5\% CCS; 2 , LNCaP cells treated with $10 \mathrm{nM}$ DHT for 24 h; 3, PC-3 cells; 4, DU145 cells; 5, PrSC; 6, PCaSC-1; 7, PCaSC-2; 8, PCaSC-5; 9, PCaSC-6; 10, PCaSC-7; 11, PCaSC-8; 12, PCaSC-9; 13, BDSC-1; 14, BDSC-2. 
level of type 5 17 $\beta$-HSD (aldo-keto reductase, AKR1C3), which is believed to catalyze the transformation of DHEA and adione into adiol and testosterone respectively (Dufort et al. 1999), is expressed at different levels among stromal cells, although LNCaP cells show a low level of expression. The expression level of type $517 \beta-\mathrm{HSD}$ of PrSC and PCaSC-8 was not correlated with DHEA-induced PSA promoter activity in the presence of PrSC or PCaSC-8.

Testosterone is converted to DHT by SRD5A in the prostate. Until now, three types of SRD5A were identified (Andersson \& Russell 1990, Andersson et al. 1991, Labrie et al. 2005, Luu-The et al. 2008,

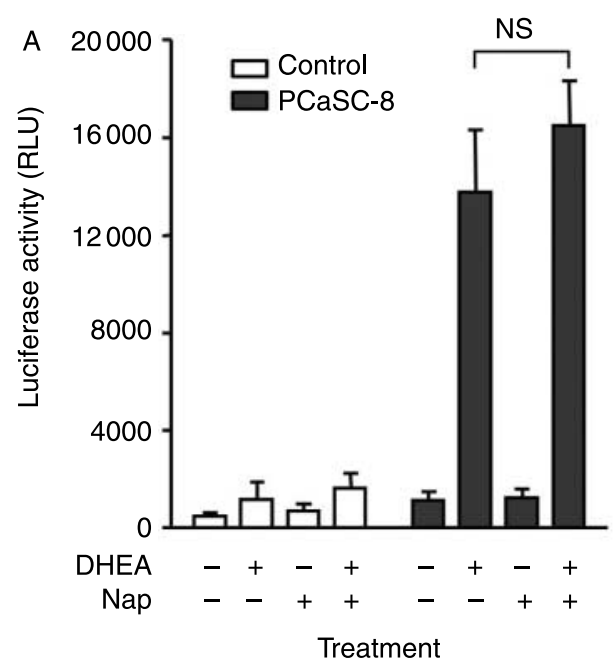

B
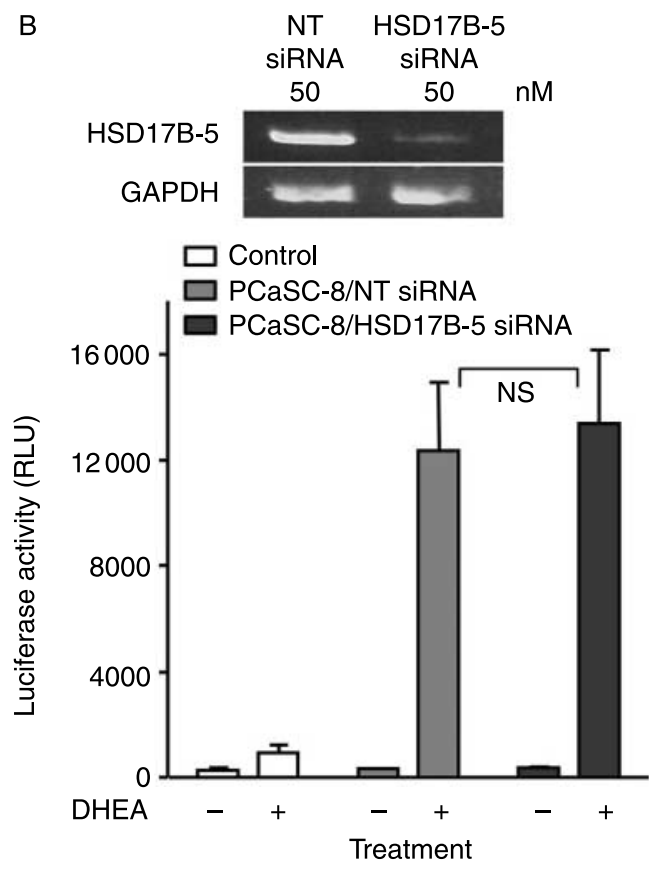

Uemura et al. 2008). Type 1 SRD5A was ubiquitously expressed in all cells compared with type 2 SRD5A. Type 3 SRD5A, which has been recently identified (Uemura et al. 2008), was expressed in LNCaP cells at a relatively high level and well expressed in all stromal cells compared with types 1 and 2 SRD5A. AKR1C2, which catalyzes the transformation from DHT into the inactive form androstane-3 $\alpha$, 17 $\beta$-diol (androstanediol), was expressed in all cells at a relatively low level, especially in $\mathrm{LNCaP}$ cells.

\section{Type 5 17 $\beta$-HSD does not contribute to testosterone biosynthesis in PrSC}

Dufort et al. (1999) reported that type $517 \beta-H S D$ may be involved in DHEA metabolism in stromal cells. This is supported by our findings that several stromal cells, including PCaSC-8, synthesized large amounts of adiol from DHEA (Fig. 3C). However, since expression levels of type $517 \beta$-HSD mRNA in stromal cells were not correlated with PSA activity as described in Fig. 2C, we focused on the activity (as opposed to expression level) of type $517 \beta-$ HSD. In order to inhibit type $517 \beta$-HSD activity, we used naproxen, which is a non-steroidal anti-inflammatory drug and an AKR1C3 inhibitor (Gobec et al. 2005). Naproxen did not inhibit PCaSC-8-induced DHEA activity in the coculture of LNCaP and PCaSC-8 cells (Fig. 5B). To further confirm these data, we cocultured LNCaP cells with PCaSC-8 in which type $517 \beta$-HSD was knocked down using shRNA. Knockdown of type 5 17 $\beta$-HSD expression in PCaSC-8 did not repress DHEA-inducted PSA promoter activity (Fig. 5C). These data suggest that type $517 \beta$-HSD does not significantly contribute to the conversion of adione into testosterone in PCaSC.

Figure 5 Effect of type 5 17 $\beta$-HSD on DHEA-induced PSA promoter activity. (A) Effect of HSD17B-5 inhibitor, naproxen, and HSD17B-5 shRNA on DHEA-induced PSA promoter activity. After $5 \times 10^{4} \mathrm{LNCaP}$ cells were transfected with $0.4 \mu \mathrm{g}$ pGL-5.8PSAp for $12 \mathrm{~h}$, the cells were cocultured with 0 or $5 \times 10^{4}$ PCaSC- 8 cells for $12 \mathrm{~h}$. Consequently, both cells were treated with $100 \mathrm{nM}$ DHEA in the absence or presence of $5 \mu \mathrm{M}$ naproxen for $24 \mathrm{~h}$, and then the absolute luciferase activities were measured. (B) Knockdown of HSD17B-5 mRNA and PSA promoter activity. After PCaSC-8 was transfected with $50 \mathrm{nM}$ HSD17B-5 siRNA for $48 \mathrm{~h}$, RNA was purified and subjected to RT-PCR of HSD17B-5 mRNA. As a negative control, $100 \mathrm{nM}$ non-targeting (NT) siRNA was also transfected. LNCaP cells transfected with pGL-5.8PSAp were cocultured with siRNAtransfected PCaSC-8. Then, LNCaP and PCaSC-8 cells were treated with $100 \mathrm{nM}$ DHEA for $24 \mathrm{~h}$ and luciferase activities were measured. These coculture experiments were performed at least twice with reproducible data. The data are presented as the mean \pm s.D. of triplicate measurements. NS means not statistically significant difference. 


\section{Effect of a dual $5 \alpha$-reductase inhibitor on DHT biosynthesis in stromal cells}

Since SRD5A types 1 and 3 are expressed in all stromal cells and DHT is synthesized from DHEA in stromal cells, we investigated whether the dual $5 \alpha$-reductase inhibitor, Dut, could block DHEA-induced PSA promoter activity in the presence of stromal cells. Coculture of LNCaP cells with PCaSC- 8 or -9 increased DHEA-induced PSA promoter activity to 10- or 30-fold respectively (Fig. 6A). Five micromolar Dut significantly inhibited PSA promoter activity induced by $100 \mathrm{nM}$ DHEA as well as $0.1 \mathrm{nM}$ testosterone, regardless of the presence of PCaSC-8 or -9 . Simultaneously, we investigated how testosterone was metabolized in LNCaP monoculture by Dut and how DHEA was metabolized to other androgens by PCaSC- 8 and -9 in the presence of Dut. When LNCaP cells were treated with testosterone in the presence of $5 \mu \mathrm{M}$ Dut, there was minimal production of DHT, and the metabolism of testosterone was reduced in the medium after $24 \mathrm{~h}$ (Fig. 6B). Dut inhibited conversion of DHEA to DHT in the LNCaP and PCaSC-8 or -9 coculture (Fig. 6C). Dut also inhibited testosterone biosynthesis from DHEA in LNCaP cells by $\sim 80 \%$ at $24 \mathrm{~h}$. This inhibition of testosterone biosynthesis was

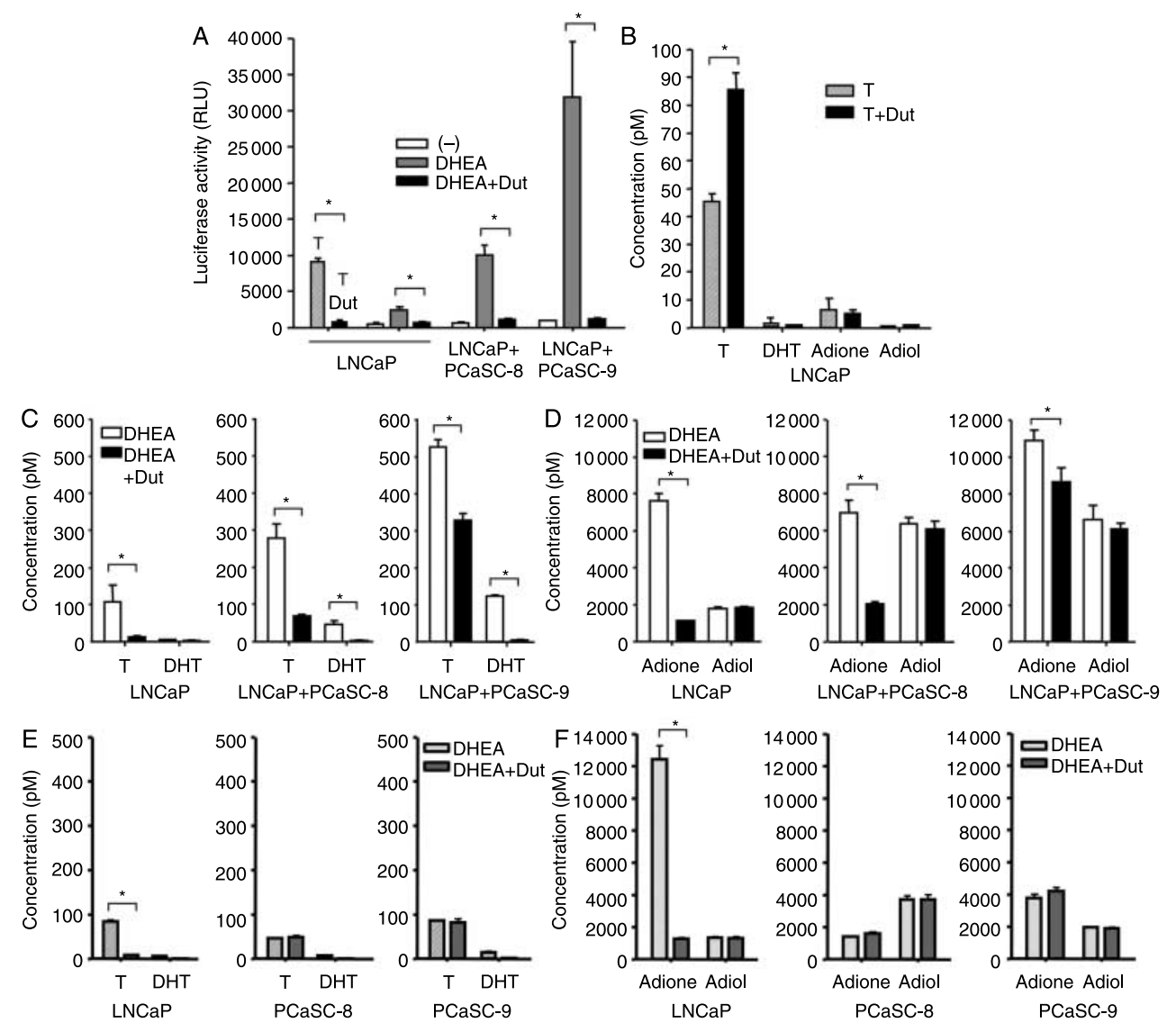

Figure 6 Effect of $5 \alpha$-reductase inhibitor, dutasteride, on testosterone or DHEA-induced PSA promoter activity and concentration of various androgens in the medium. (A) After $5 \times 10^{4}$ LNCaP cells were transfected with $0.4 \mu \mathrm{g}$ pGL-5.8PSAp for $12 \mathrm{~h}$, the cells were cocultured with $5 \times 10^{4}$ PCaSC- 8 or PCaSC- 9 cells or without stromal cells for $12 \mathrm{~h}$. Consequently, both cells were treated with $100 \mathrm{nM}$ DHEA with or without $5 \mu \mathrm{M}$ dutasteride (Dut) for $24 \mathrm{~h}$, and luciferase assay was performed. As a positive control, transfected $\mathrm{LNCaP}$ cells were treated with $0.1 \mathrm{nM}$ testosterone for $24 \mathrm{~h}$. These coculture experiments were performed at least twice with reproducible data. The data are presented as the mean \pm s.D. of triplicate measurements. (B) Concentration of testosterone, DHT, adione, and adiol in the medium treated with $0.1 \mathrm{nM}$ testosterone with or without Dut. Twenty-four hours after treating cocultured $\mathrm{LNCaP}$ cells in the presence of $0.1 \mathrm{nM}$ testosterone with or without Dut, the medium was collected for LC-ESI-MS/MS as described in Fig. 3. (C and D) Concentration of testosterone and DHT (C), adione and adiol (D) in the medium treated with $100 \mathrm{nM}$ DHEA with or without dutasteride. Twenty-four hours after treating cocultured LNCaP cells with PCaSC-8 or -9 in the presence of 100 nM DHEA with or without Dut, the medium was collected for LC-ESI-MS/MS. (E and F) Concentration of testosterone and DHT (E), and adione and adiol $(F)$ in the medium of LNCaP, PCaSC-8, and PCaSC-9 monocultures treated with DHEA with or without dutasteride. Twenty-four hours after treating LNCaP cells, PCaSC-8, and PCaSC-9 in the presence of $100 \mathrm{nM} \mathrm{DHEA}$ with or without dutasteride, the medium was collected for LC-ESI-MS/MS. The data are presented as the mean \pm S.D. of triplicate measurements. 
also observed in coculture with PCaSC- 8 or -9 by $\sim 75$ and $66 \%$ respectively (Fig. $6 \mathrm{C}$ ). We also measured the concentration of adione and adiol $24 \mathrm{~h}$ after DHEA and Dut treatments (Fig. 6D). The concentration of adione was decreased by Dut in accordance with the decrease in the concentration of testosterone. In contrast, the concentration of adiol was not changed by Dut regardless of PCaSCs.

\section{Comparison of androgen concentrations on coculture with those on PCaSC-8 and -9 monoculture}

The androgen concentrations measured in Fig. 6C and $\mathrm{D}$ were totals of androgens metabolized by $\mathrm{LNCaP}$ cells and PCaSC- 8 or -9 . Therefore, we measured the androgen concentrations in medium of monoculture cells treated with DHEA for $24 \mathrm{~h}$ (Fig. $6 \mathrm{E}$ and F). The sum of testosterone and DHT concentrations from the monocultures of the $\mathrm{LNCaP}$ cells and the PCaSCs was less than testosterone and DHT concentrations in coculture without Dut (compare Fig. 6E with C). This suggests that the presence of the two cell types in the coculture stimulates testosterone and DHT synthesis in a synergistic fashion. On the other hand, LNCaP cells produced much higher levels of adione in monoculture than either PCaSC line (Fig. 6F). The total adione in the coculture approximates that of the LNCaP monoculture (compare Fig. 6D with F), suggesting that, in coculture, the total adione may be primarily due to production by $3 \beta$-HSD in LNCaP cells, although this has not been definitively demonstrated. The adiol levels in coculture with PCaSC- 8 or -9 were more than the sum of adiol produced from DHEA by the monocultures (compare Fig. 6D with F). This suggests that the presence of the two cell types in the coculture stimulates adiol synthesis in a synergistic fashion.

We also examined the effect of Dut on the androgen levels in coculture versus monocultures. Five micromolar Dut inhibited DHT synthesis from testosterone in LNCaP, PCaSC-8, and PCaSC-9 monocultures and also adione synthesis from DHEA in LNCaP monoculture. However, Dut did not inhibit adione synthesis in PCaSC8 and -9 (Fig. 6F). This result indicates that reduction of testosterone concentration observed in coculture in the presence of Dut is due to inhibition of adione synthesis by Dut in LNCaP cells, but not PCaSCs.

\section{Discussion}

The present study shows that PrSC can increase AR activity induced by the adrenal precursor DHEA in androgen-sensitive $\mathrm{PCa}$ cells and stimulate the proliferation of PCa cells. Furthermore, PCaSC and BDSC induce greater androgen activity than PrSC or lung-derived stromal cells. The physiological concentration of serum DHEA is between 3 and $15 \mathrm{nM}$, although that of DHEA-sulfate (DHEA-S) ranges between 1 and $10 \mu \mathrm{M}$. This concentration of DHEA did not stimulate the proliferation during monoculture of LNCaP cells. We also confirmed that $10 \mu \mathrm{M}$ DHEA$\mathrm{S}$ had almost no ability to activate AR even in the presence of stromal cells (data not shown), thus suggesting that the LNCaP and stromal cells studied have little steroid sulfatase activity.

Our results show that physiological concentrations of DHEA stimulate the proliferation of LNCaP cells in the presence of stromal cells, especially cancer-derived stromal cells. The present data strongly suggest that biosynthesis of testosterone and DHT in stromal cells mediates paracrine stimulation of $\mathrm{PCa}$ cells. This activity could readily contribute to androgen deprivation-refractory PCa after ADT. Recently, Arnold et al. (2008) have described a similar study using coculture of LAPC4 androgen-sensitive PCa cells with stromal cells. According to their study, PCa-derived stromal cells also increased PSA mRNA expression induced by DHEA. However, they did not identify that the proliferation of LAPC4 cells was stimulated by DHEA in the presence of PCa-derived stromal cells in contrast to the proliferation of LNCaP cells in our study. The difference between our study and their study may be due to a difference in sensitivity for androgens between LNCaP and LAPC4.

Several mechanisms explaining why advanced $\mathrm{PCa}$ relapses during ADT have been considered (Feldman \& Feldman 2001, Schroder 2008). AR amplification, action of cytokines on the AR, induction of AR coactivators, or STAT-3 activation (Fujimoto et al. 2001, Harada et al. 2001, Chen et al. 2004) all can cause an androgen-hypersensitive state in PCa. It has also been shown that coculture of stromal cells with PCa-derived epithelial cells enhanced AR activity via recruitment of coregulators (Cano et al. 2007). Pathways that are involved in the development of treatment-resistant $\mathrm{PCa}$ are also related to the microenvironment surrounding cancer cells. In fact, $\mathrm{PCa}$-stroma interactions play an important key factor for prostate development and carcinogenesis (Cunha et al. 2004). Increased expression of chemokines, cytokines, and growth factors from stromal cells drives PCa cells to a more invasive and malignant state (Sung \& Chung 2002, Kaminski et al. 2006, Le et al. 2006). Accordingly, alterations in the stromal microenvironment as well as PCa cells themselves cooperate to promote malignant transformation of $\mathrm{PCa}$. 
It is very likely that residual androgens in PCa tissue are involved in the progression of PCa that has become androgen hypersensitive. Our data indicate that the adrenal androgen precursor DHEA acts as precursor for synthesis of residual androgens in PCa tissues. Recently, many physicians have adopted combined androgen blockade using an LHRH agonist and an antiandrogen as initial treatment for advanced PCa. However, metastatic PCa relapses and serum PSA values increase a few years later. Ketoconazole that inhibits the synthesis of adrenal DHEA is often used for HRPC in West European countries and has a response rate of about $60 \%$, but the response is of short duration. Furthermore, in phase II studies using the CYP17A inhibitor abiraterone, which blocks DHEA synthesis, PSA declines of $>50 \%$ in 12 out of 21 (57\%) patients have been observed (Attard et al. 2008), although cessation of the antiandrogen, by itself, could have caused a significant effect on PSA. These results suggest that adrenal DHEA contributes to $>50 \%$ of relapses of advanced metastatic PCa.

Even after ADT, DHT remains in the PCa tissue at $20-40 \%$ of untreated prostate tissue, although serum DHT levels decrease to $<10 \%$ after ADT (Labrie et al. 1985, 1993, Mizokami et al. 2004, Nishiyama et al. 2004). Mohler et al. (2004) demonstrated that recurrent PCa tissue retains testosterone at around $50 \%$ of benign prostatic tissue. Recently, Montgomery et al. (2008) has demonstrated that testosterone levels within metastases from anorchid men were significantly higher than levels within primary $\mathrm{PCa}$ from untreated eugonadal men. These reports indicate that testosterone and DHT accumulate in PCa tissue and metastatic lesions after ADT. These data as well as the presence of steroidogenic enzymes in PCa tissue strongly suggest that testosterone is synthesized from adrenal DHEA not only in the testes but also in PCa tissue and metastatic lesions by 'intracrine synthesis' (Labrie et al. 1985, 2005).

The mechanisms through which testosterone and DHT are synthesized in PCa tissue and how they contribute to $\mathrm{PCa}$ progression are unclear. Our data indicate that stromal cells promote androgen production in PCa either directly or through simulation of PCa epithelial cell-mediated production of androgens. The PSA promoter activity induced by DHEA was only moderate in LNCaP monocultures. However, coculture with stromal cells, especially PCaSCs, strongly activated PSA promoter activity induced by DHEA. Although our results are consistent with Arnold et al. (2008) observation that testosterone synthesized from DHEA in PCa-derived stromal cells contributed to PSA induction in LAPC4, we extended these studies further to elucidate which pathways were involved in testosterone synthesis. Specifically, we identified that the increased level of DHEAinduced AR activity by stromal cells was dependent on the synthesized level of testosterone and DHT achieved by coculture. (Figs 3 and 6). Furthermore, the ability and the predominant pathways (via adiol and/or via adione) of testosterone biosynthesis from DHEA were dependent on stromal cells. These results suggest that enzymatic activities, which catalyze conversion of DHEA to testosterone or DHT via adiol or adione, differ among stromal cells and coordinately with cancer cells.

When we examined the expression of androgen biosynthesis enzymes, expression pattern was different among each of stromal cells. Furthermore, the expression pattern of type $517 \beta$-HSD in stromal cells, whose expression has been reported to be increased in PCa (Fung et al. 2006), did not correlate with increase in DHEA-induced PSA promoter activity by stromal cells. This discrepancy may be due to several reasons: 1) expression level of androgen biosynthesis enzymes mRNA does not always reflect its enzymatic activity; 2) total activity of all $17 \beta$-HSDs may be important for the global conversion of DHEA to adiol or adione to testosterone; and 3) recently, type $1517 \beta$-HSD has been proposed to convert adione to testosterone and thus may impact the overall response (Luu-The et al. 2008).

DHT is usually synthesized from testosterone by SRD5A1 and 2 in the prostate. Although SRD5A2 is predominantly expressed in the normal prostate, recent evidence shows that SRD5A1 is highly expressed in $\mathrm{PCa}$ and HRPC, whereas SRD5A2 is not highly expressed (Thomas et al. 2008). Consistent with this finding, we also observed that SRD5A1 was highly expressed in $\mathrm{LNCaP}$ cells and in all stromal cells. Uemura et al. (2008) discovered SRD5A3 in HRPC. SRD5A3 is predominantly expressed in HRPC, but not in androgen-sensitive PCa. We observed that both LNCaP cells and PCaSC from PCa patients expressed SRD5A3 mRNA, and that Dut almost completely blocked PSA promoter activity induced by testosterone and DHEA in the presence or absence of stromal cells. Dut may inhibit SRD5A3 activity as well as SRD5A1 and SRD5A2 activity. Interestingly, when LNCaP cells were treated with DHEA regardless of the presence or absence of stromal cells, Dut inhibited not only DHT biosynthesis but also testosterone and adione biosynthesis from DHEA in LNCaP cells. However, inhibition of adione biosynthesis from DHEA by Dut was not observed in PCaSC-8 and -9 (Fig. 6F). It is not clear why Dut inhibited adione synthesis only in 

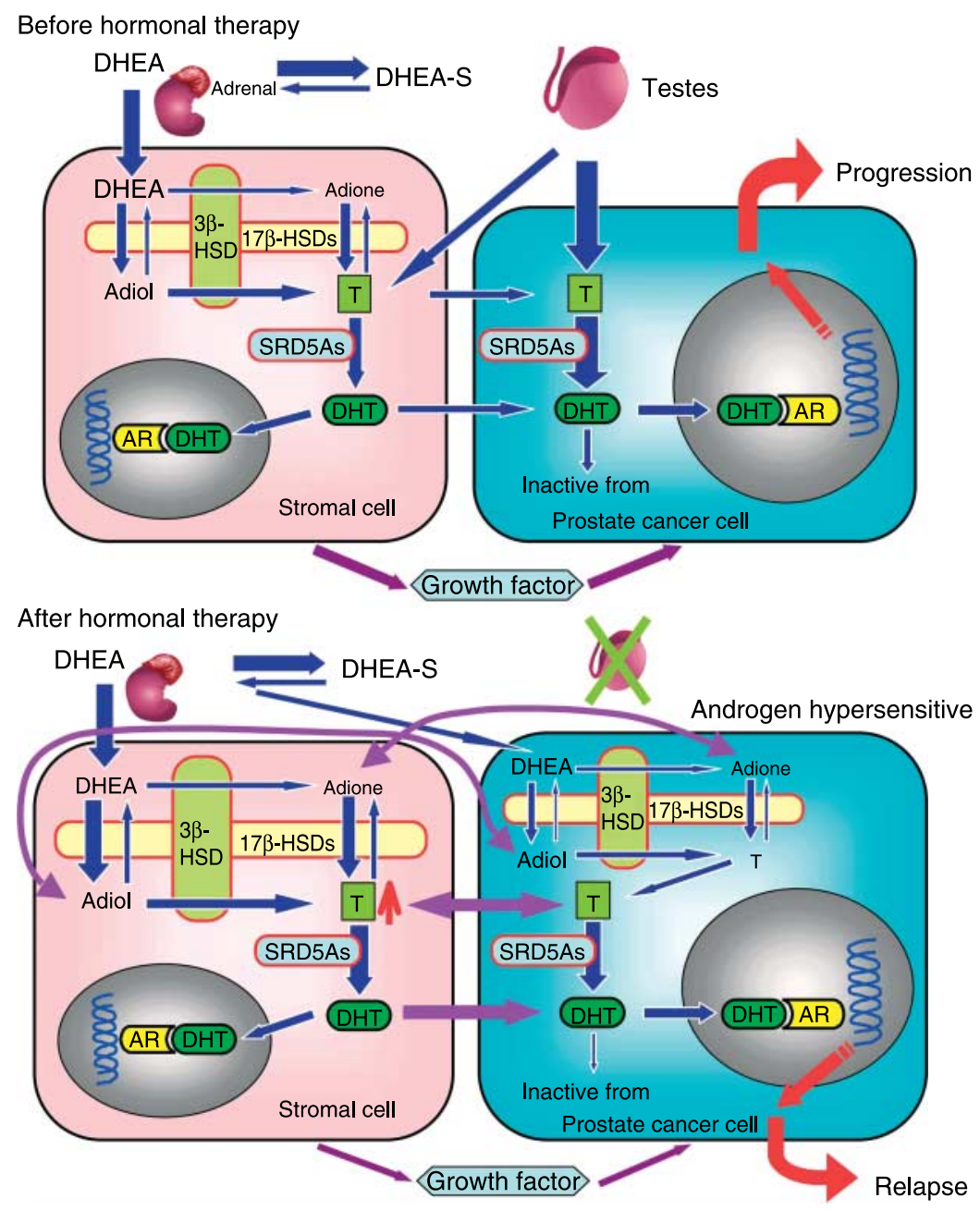

Figure 7 Mechanism of how DHEA contributes to androgen therapy non-responsive PCa. Prior to androgen deprivation therapy (ADT), testosterone from the testes plays a major role in the androgen activity in the prostate, whereas the adrenal androgen DHEA plays a minor role. After ADT, in addition to the growth factors and cytokines from PCa-derived stromal cells that stimulate the proliferation of $\mathrm{PCa}$, residual $\mathrm{PCa}$ cells become androgen hypersensitive through various mechanisms and simultaneously PCaderived stromal cells synthesize testosterone, DHT, and precursors from DHEA coordinately. These synthesized androgens induce $\mathrm{AR}$ activity and stimulate the progression of $\mathrm{PCa}$ in a paracrine fashion.

LNCaP cells. Recently, Lazier et al. (2004) have demonstrated that Dut not only inhibits the conversion from testosterone to DHT but also acted as an antiandrogen. We also confirmed that Dut inhibited PSA promoter activity induced by DHT in LNCaP cells (data not shown). Taken together, Dut may have a variety of inhibitory functions on androgen biosynthesis and AR action.

On the basis of our data and previous reports, we propose an interactive model for the interaction between $\mathrm{PCa}$ cells and the surrounding stromal cells (Fig. 7). The proliferation of $\mathrm{PCa}$ is highly dependent upon testosterone and DHT secreted from the testes, the testosterone of testicular origin adds to the testosterone made locally from DHEA
(Labrie et al. 2005). Although ADT induces apoptosis of many PCa epithelial cells, stromal cells surrounding $\mathrm{PCa}$ cells can still survive. Then oncogenes, cytokines, and growth factors may affect survival and progression, especially when only partial androgen blockade or monotherapy is used. On the other hand, PCaSC can synthesize testosterone and DHT from DHEA coordinately with cancer cells and secrete them to the surrounding area in a paracrine fashion. Surviving PCa cells receive an androgenic supply from stromal cells, and progression of the cancer continues. However, we cannot eliminate that some growth factors or cytokines induced by DHEA in either stromal or epithelial cells affect LNCaP proliferation independent of AR. 
In conclusion, we have demonstrated that the concentration of testosterone and DHT in PCa tissue is higher than in serum after ADT. This results from biosynthesis of testosterone from DHEA in PCaderived tissues. It is possible that both stromal and epithelial cells may contribute to the conversion of DHEA to testosterone. Our coculture assay system is extremely useful for measuring total DHEA activity, which results in AR activation in $\mathrm{PCa}$ and stromal cells. Such data could support the development of new drugs to inhibit biosynthesis of androgens. Moreover, using this assay system, there may be a possibility of predicting relapse and the time of relapse at diagnosis of advanced PCa, depending upon the level of steroidogenic enzyme expression. In the present study, we used stromal cells from high-grade $\mathrm{PCa}$ tissue (Gleason 7, 8, and 9). It would be interesting if we could culture stromal cells from low-grade PCa tissue and perform the same study; however, these were not readily available for our studies. Additional studies are needed to assess which enzymes are the most involved in the biosynthesis of androgens in $\mathrm{PCa}$ tissue. The present data also indicate that monotherapy of PCa with medical or surgical castration alone or an antiandrogen alone is an insufficient treatment for $\mathrm{PCa}$ at any stage of the disease, due to the major importance of the local biosynthesis of androgens from DHEA.

\section{Declaration of interest}

The authors declare that there is no conflict of interest that could be perceived as prejudicing the impartiality of the research reported.

\section{Funding}

A Grant-in-Aid for Scientific Research on Priority Areas from the Ministry of Education, Culture, Sport, Science, and Technology of Japan. This work was also supported, in part, by NCI PO1 CA093900.

\section{Acknowledgements}

We thank S Fuji and Y Kawabuchi for technical assistance.

\section{References}

Akaza H 2007 Global update on defining and treating highrisk localized prostate cancer with leuprorelin: a Japanese perspective - the effect of primary androgen deprivation therapy on stage $\mathrm{C}$ prostate cancer. BJU International 99 10-12 (discussion 17-18).

Andersson S \& Russell DW 1990 Structural and biochemical properties of cloned and expressed human and rat steroid 5 $\alpha$-reductases. PNAS 87 3640-3644.
Andersson S, Berman DM, Jenkins EP \& Russell DW 1991 Deletion of steroid $5 \alpha$-reductase 2 gene in male pseudohermaphroditism. Nature 354 159-161.

Arnold JT, Le H, McFann KK \& Blackman MR 2005 Comparative effects of DHEA vs. testosterone, dihydrotestosterone, and estradiol on proliferation and gene expression in human $\mathrm{LNCaP}$ prostate cancer cells. American Journal of Physiology 288 E573-E584.

Arnold JT, Gray NE, Jacobowitz K, Viswanathan L, Cheung PW, McFann KK, Le H \& Blackman MR 2008 Human prostate stromal cells stimulate increased PSA production in DHEA-treated prostate cancer epithelial cells. Journal of Steroid Biochemistry and Molecular Biology 111 240-246.

Attard G, Reid AH, Yap TA, Raynaud F, Dowsett M, Settatree S, Barrett M, Parker C, Martins V, Folkerd E et al. 2008 Phase I clinical trial of a selective inhibitor of CYP17, abiraterone acetate, confirms that castrationresistant prostate cancer commonly remains hormone driven. Journal of Clinical Oncology 26 4563-4571.

Belanger B, Belanger A, Labrie F, Dupont A, Cusan L \& Monfette G 1989 Comparison of residual C-19 steroids in plasma and prostatic tissue of human, rat and guinea pig after castration: unique importance of extratesticular androgens in men. Journal of Steroid Biochemistry 32 695-698.

Cano P, Godoy A, Escamilla R, Dhir R \& Onate SA 2007 Stromal-epithelial cell interactions and androgen receptor-coregulator recruitment is altered in the tissue microenvironment of prostate cancer. Cancer Research 67 511-519.

Chen CD, Welsbie DS, Tran C, Baek SH, Chen R, Vessella R, Rosenfeld MG \& Sawyers CL 2004 Molecular determinants of resistance to antiandrogen therapy. Nature Medicine 10 33-39.

Cunha GR, Cooke PS \& Kurita T 2004 Role of stromalepithelial interactions in hormonal responses. Archives of Histology and Cytology 67 417-434.

Dufort I, Rheault P, Huang XF, Soucy P \& Luu-The V 1999 Characteristics of a highly labile human type 5 $17 \beta$-hydroxysteroid dehydrogenase. Endocrinology 140 568-574.

Feldman BJ \& Feldman D 2001 The development of androgen-independent prostate cancer. Nature Reviews. Cancer $134-45$.

Forti G, Salerno R, Moneti G, Zoppi S, Fiorelli G, Marinoni T, Natali A, Costantini A, Serio M, Martini L et al. 1989 Three-month treatment with a long-acting gonadotropinreleasing hormone agonist of patients with benign prostatic hyperplasia: effects on tissue androgen concentration, $5 \alpha$ reductase activity and androgen receptor content. Journal of Clinical Endocrinology and Metabolism $\mathbf{6 8}$ 461-468.

Fujimoto N, Mizokami A, Harada S \& Matsumoto T 2001 Different expression of androgen receptor coactivators in human prostate. Urology 58 289-294. 
Fung KM, Samara EN, Wong C, Metwalli A, Krlin R, Bane B, Liu CZ, Yang JT, Pitha JV, Culkin DJ et al. 2006 Increased expression of type $23 \alpha$-hydroxysteroid dehydrogenase/type $517 \beta$-hydroxysteroid dehydrogenase (AKR1C3) and its relationship with androgen receptor in prostate carcinoma. Endocrine-Related Cancer $\mathbf{1 3}$ 169-180.

Geissler WM, Davis DL, Wu L, Bradshaw KD, Patel S, Mendonca BB, Elliston KO, Wilson JD, Russell DW \& Andersson S 1994 Male pseudohermaphroditism caused by mutations of testicular $17 \beta$-hydroxysteroid dehydrogenase 3. Nature Genetics 7 34-39.

Gobec S, Brozic P \& Rizner TL 2005 Nonsteroidal antiinflammatory drugs and their analogues as inhibitors of aldo-keto reductase AKR1C3: new lead compounds for the development of anticancer agents. Bioorganic and Medicinal Chemistry Letters 15 5170-5175.

Harada S, Keller ET, Fujimoto N, Koshida K, Namiki M, Matsumoto T \& Mizokami A 2001 Long-term exposure of tumor necrosis factor $\alpha$ causes hypersensitivity to androgen and anti-androgen withdrawal phenomenon in LNCaP prostate cancer cells. Prostate 46 319-326.

Jemal A, Siegel R, Ward E, Hao Y, Xu J, Murray T \& Thun MJ 2008 Cancer statistics, 2008. CA: A Cancer Journal for Clinicians 58 71-96.

Kaminski A, Hahne JC, Haddouti el-M, Florin A, Wellmann A \& Wernert N 2006 Tumour-stroma interactions between metastatic prostate cancer cells and fibroblasts. International Journal of Molecular Medicine 18 941-950.

Krill D, Shuman M, Thompson MT, Becich MJ \& Strom SC 1997 A simple method for the isolation and culture of epithelial and stromal cells from benign and neoplastic prostates. Urology 49 981-988.

Labrie F 1991 Intracrinology. Molecular and Cellular Endocrinology 78 C113-C118.

Labrie F 2007 Multiple intracrine hormonal targets in the prostate: opportunities and challenges. BJU International 100 48-51.

Labrie F, Dupont A \& Belanger A 1985 Complete androgen blockade for the treatment of prostate cancer. Important Advances in Oncology 193-217.

Labrie F, Belanger A, Dupont A, Luu-The V, Simard J \& Labrie C 1993 Science behind total androgen blockade: from gene to combination therapy. Clinical and Investigative Medicine 16 475-492.

Labrie F, Luu-The V, Belanger A, Lin SX, Simard J, Pelletier G \& Labrie C 2005 Is dehydroepiandrosterone a hormone? Journal of Endocrinology 187 169-196.

Lazier CB, Thomas LN, Douglas RC, Vessey JP \& Rittmaster RS 2004 Dutasteride, the dual $5 \alpha$-reductase inhibitor, inhibits androgen action and promotes cell death in the LNCaP prostate cancer cell line. Prostate $\mathbf{5 8}$ 130-144.

Le H, Arnold JT, McFann KK \& Blackman MR 2006 DHT and testosterone, but not DHEA or $\mathrm{E}_{2}$, differentially modulate IGF-I, IGFBP-2, and IGFBP-3 in human prostatic stromal cells. American Journal of Physiology 290 E952-E960.
Lu Y, Zhang J, Dai J, Dehne LA, Mizokami A, Yao Z \& Keller ET 2004 Osteoblasts induce prostate cancer proliferation and PSA expression through interleukin-6mediated activation of the androgen receptor. Clinical and Experimental Metastasis 21 399-408.

Luu-The V, Belanger A \& Labrie F 2008 Androgen biosynthetic pathways in the human prostate. Best Practice and Research. Clinical Endocrinology and Metabolism 22 207-221.

Mizokami A, Gotoh A, Yamada H, Keller ET \& Matsumoto T 2000 Tumor necrosis factor- $\alpha$ represses androgen sensitivity in the LNCaP prostate cancer cell line. Journal of Urology 164 800-805.

Mizokami A, Koh E, Fujita H, Maeda Y, Egawa M, Koshida K, Honma S, Keller ET \& Namiki M 2004 The adrenal androgen androstenediol is present in prostate cancer tissue after androgen deprivation therapy and activates mutated androgen receptor. Cancer Research 64 765-771.

Mohler JL, Gregory CW, Ford OH III, Kim D, Weaver CM, Petrusz P, Wilson EM \& French FS 2004 The androgen axis in recurrent prostate cancer. Clinical Cancer Research 10 440-448.

Montgomery RB, Mostaghel EA, Vessella R, Hess DL, Kalhorn TF, Higano CS, True LD \& Nelson PS 2008 Maintenance of intratumoral androgens in metastatic prostate cancer: a mechanism for castration-resistant tumor growth. Cancer Research 68 4447-4454.

Nishiyama T, Hashimoto Y \& Takahashi K 2004 The influence of androgen deprivation therapy on dihydrotestosterone levels in the prostatic tissue of patients with prostate cancer. Clinical Cancer Research 10 7121-7126.

Pelletier G, Luu-The V, El-Alfy M, Li S \& Labrie F 2001 Immunoelectron microscopic localization of $3 \beta$ hydroxysteroid dehydrogenase and type $517 \beta$-hydroxysteroid dehydrogenase in the human prostate and mammary gland. Journal of Molecular Endocrinology 26 11-19.

Schroder FH 2008 Progress in understanding androgenindependent prostate cancer (AIPC): a review of potential endocrine-mediated mechanisms. European Urology 53 1129-1137.

Stanbrough M, Bubley GJ, Ross K, Golub TR, Rubin MA, Penning TM, Febbo PG \& Balk SP 2006 Increased expression of genes converting adrenal androgens to testosterone in androgen-independent prostate cancer. Cancer Research 66 2815-2825.

Sung SY \& Chung LW 2002 Prostate tumor-stroma interaction: molecular mechanisms and opportunities for therapeutic targeting. Differentiation; Research in Biological Diversity 70 506-521.

Takeda H, Akakura K, Masai M, Akimoto S, Yatani R \& Shimazaki J 1996 Androgen receptor content of prostate carcinoma cells estimated by immunohistochemistry is related to prognosis of patients with stage D2 prostate carcinoma. Cancer 77 934-940. 
Taplin ME \& Balk SP 2004 Androgen receptor: a key molecule in the progression of prostate cancer to hormone independence. Journal of Cellular Biochemistry 91 483-490.

Thomas LN, Douglas RC, Lazier CB, Too CK, Rittmaster RS $\&$ Tindall DJ 2008 Type 1 and type 2 5a-reductase expression in the development and progression of prostate cancer. European Urology 53 244-252.

Titus MA, Schell MJ, Lih FB, Tomer KB \& Mohler JL 2005 Testosterone and dihydrotestosterone tissue levels in recurrent prostate cancer. Clinical Cancer Research 11 4653-4657.
Uemura M, Tamura K, Chung S, Honma S, Okuyama A, Nakamura Y \& Nakagawa H 2008 Novel 5 $\alpha$-steroid reductase (SRD5A3, type-3) is overexpressed in hormonerefractory prostate cancer. Cancer Science 99 81-86.

Veldscholte J, Ris-Stalpers C, Kuiper GG, Jenster G, Berrevoets C, Claassen E, van Rooij HC, Trapman J, Brinkmann AO \& Mulder E 1990 A mutation in the ligand binding domain of the androgen receptor of human LNCaP cells affects steroid binding characteristics and response to anti-androgens. Biochemical and Biophysical Research Communications 173 534-540. 